\title{
Águas urbanas
}

\section{CARLOS E. M. TUCCI}

\section{Desenvolvimento urbano}

\section{Estrutura urbana}

$\mathrm{O}$ DESENVOLVIMENTO urbano se acelerou na segunda metade do século XX com a concentração da população em espaço reduzido, produzindo grande competição pelos mesmos recursos naturais (solo e água), destruindo parte da biodiversidade natural. O meio formado pelo ambiente natural e pela população (socioeconômico urbano) é um ser vivo e dinâmico que gera um conjunto de efeitos interligados, que sem controle pode levar a cidade ao caos.

O desenvolvimento sustentável urbano tem o objetivo de melhorar a qualidade da vida da população e a conservação ambiental. É também essencialmente integrador na medida em que a qualidade de vida somente é possível com um ambiente conservado que atenda às necessidades da população, garantindo harmonia do homem e da natureza.

Os principais componentes da estrutura da gestão da cidade envolvem os seguintes elementos:

- Planejamento e gestão do uso do solo: trata da definição, por meio do Plano Diretor Urbano, de como a cidade é prevista para ser ocupada e suas correções com relação ao cenário do passado e do presente;

- Infra-estrutura viária, água, energia, comunicação e transporte: planejamento e gestão desses componentes da infra-estrutura que podem ser de atribuição de implantação pública ou privada, mas devem estar regulados pelo município;

- Gestão socioambiental: a gestão do meio ambiente urbano é realizada por entidades municipais, estaduais ou federais de acordo com a estrutura institucional. A gestão envolve a avaliação e aprovação de projetos, monitoramento, fiscalização e pesquisa para que o desenvolvimento urbano seja socioambiental sustentável.

\section{Indicadoves}

Os sistemas urbanos ${ }^{1}$ são primordialmente áreas de consumo e moradia. Possuem diferentes dimensões ou integração de várias áreas como Regiões Metropolitanas. Em 1900, 13\% da população mundial eram urbanas, atualmente chegam a $50 \%$, ocupando apenas $2,8 \%$ do território do globo. A população urbana no Brasil chega a 83\%. Em 2010 está previsto que 50,8\% da população urbana do mundo estarão na Ásia e 13,4\%, na América Latina e Caribe. O mundo está se tornando cada vez mais urbano em razão do desenvolvimento econômico, gerando pressão sobre o ambiente ocupado pela urbanização. 
Os principais indicadores do desenvolvimento urbano são os seguintes:

- População: taxa de crescimento, migração e densificação urbana;

- Econômico: renda, produto bruto e perfil de produção;

- Uso do solo: distribuição por tipo de uso do espaço urbano em residencial, comercial e industrial, áreas públicas.

A urbanização aumenta com o crescimento econômico, quando o perfil da renda se altera e o emprego se concentra mais nos serviços e na indústria do que na agricultura. Com a urbanização, a taxa de natalidade tende a diminuir em razão de vários fatores sociais.

O crescimento urbano ocorrido nas últimas décadas transformou o Brasil num país essencialmente urbano ( $83 \%$ de população urbana). Esse processo se deu especialmente nas Regiões Metropolitanas (RM) e nas cidades que se transformaram em pólos regionais. As RM possuem um núcleo principal com várias cidades circunvizinhas. A taxa de crescimento do núcleo da RM é pequena, enquanto o crescimento da periferia é muito alto. As cidades acima de um milhão de habitantes crescem a uma taxa média de 0,9\% anual, enquanto os pólos regionais com população entre cem mil e quinhentos mil (cidades médias segundo Ipea/IBGE (MMA, 2000)) crescem a uma taxa de 4,8\% (IBGE, 1998). Todos os processos inadequados de urbanização e impacto ambiental que se observaram nas RM estão se reproduzindo nas cidades de médio porte. Cidades com população acima de cem mil habitantes correspondem a $51 \%$ da população total do país, distribuídos em 212 municípios, enquanto os trinta maiores municípios (acima de quinhentos mil) representam $27 \%$ da população.

Desde o século passado, o desenvolvimento urbano passou a criar padrões de concentração urbana. Nas grandes cidades, houve um processo de desconcentração urbana em direção à periferia, deixando o centro das cidades despovoado e degradado. Dificuldades de vias de transporte, aumento de tráfego, deterioração do transporte têm levado a mudanças de atitude nesse processo.

No Brasil, em algumas cidades, a população em área irregular ou informal chega a 50\% (MMA, 2000). O crescimento da população favelada tem sido significativo, e mesmo o seu adensamento é preocupante. O crescimento populacional ocorre especialmente na população de baixa renda, e a população favelada deve dobrar nos próximos dez anos, chegando a 13,5 milhões de pessoas. Isso reflete o déficit habitacional resultado da situação econômica, já que a participação do Estado no aumento da moradia foi da ordem de 27\% (MMA, 2000).

Os principais problemas relacionados com a infra-estrutura e a urbanização nos países em desenvolvimento, com destaque para a América Latina, são:

- Grande concentração populacional em pequena área, com deficiência no sistema de transporte, falta de abastecimento e saneamento, ar, água poluída e inundações. Essas condições ambientais inadequadas reduzem condições de saúde, qualidade de vida da população, impactos ambientais, e são as principais limitações ao seu desenvolvimento. 
- Aumento da periferia das cidades de forma descontrolada pela migração rural em busca de emprego. Esses bairros geralmente estão desprovidos de segurança, de infra-estrutura tradicional de água, esgoto, drenagem, transporte e coleta de resíduos sólidos, e são dominados por grupos de delinqüentes geralmente ligados ao tráfico de drogas.

- A urbanização é espontânea e o planejamento urbano é realizado para a cidade ocupada pela população de renda média e alta. Para áreas ilegais e públicas, existe invasão e a ocupação ocorre sobre áreas de risco como de inundações e de escorregamento, com freqüentes mortes durante o período chuvoso. Parte importante da população vive em algum tipo de favela. Portanto, existem a cidade formal e a informal. A gestão urbana geralmente atinge somente a primeira.

\section{Impactos sobre águas urbanas}

O planejamento urbano é realizado para a cidade formal, e para a cidade informal são analisadas tendências dessa ocupação. Os principais problemas relacionados com a infra-estrutura de água no ambiente urbano são:

- Falta de tratamento de esgoto: grande parte das cidades da região não possui tratamento de esgoto e lança os efluentes na rede de esgotamento pluvial, que escoa pelos rios urbanos (maioria das cidades brasileiras);

- Outras cidades optaram por implantar as redes de esgotamento sanitário (muitas vezes sem tratamento), mas não implementam a rede de drenagem urbana, sofrendo freqüentes inundações com o aumento da impermeabilização;

- Ocupação do leito de inundação ribeirinha, sofrendo freqüentes inundações;

- Impermeabilização e canalização dos rios urbanos com aumento da vazão de cheia (sete vezes) e sua freqüência; aumento da carga de resíduos sólidos e da qualidade da água pluvial sobre os rios próximos das áreas urbanas;

- Deterioração da qualidade da água por falta de tratamento dos efluentes tem criado potenciais riscos ao abastecimento da população em vários cenários, e o mais crítico tem sido a ocupação das áreas de contribuição de reservatórios de abastecimento urbano que, eutrofizados, podem produzir riscos à saúde da população.

Existe uma visão limitada do que é a gestão integrada do solo urbano e da sua infra-estrutura, e grande parte dos problemas destacados aqui foi gerada por um ou mais dos aspectos destacados a seguir:

- Falta de conbecimento: da população e dos profissionais de diferentes áreas que não possuem informações adequadas sobre os problemas e suas causas. As decisões resultam em custos altos, e algumas empresas se apóiam para aumentar seus lucros;

- Concepção inadequada dos profissionais de engenharia para o planejamento e controle dos sistemas: uma parcela importante dos engenheiros 
que atuam no meio urbano está desatualizada quanto à visão ambiental e geralmente busca soluções estruturais que alteram o ambiente, com excesso de áreas impermeáveis e conseqüente aumento de temperatura, inundações, poluição, entre outros;

- Visão setorizada do planejamento urbano: o planejamento e o desenvolvimento das áreas urbanas são realizados sem incorporar aspectos relacionados com os diferentes componentes da infra-estrutura de água. Uma parte importante dos profissionais que atuam nessa área possui uma visão setorial limitada;

- Falta de capacidade gerencial: os municípios não possuem estrutura para o planejamento e gerenciamento adequado dos diferentes aspectos da água no meio urbano.

\section{Águas urbanas}

As águas urbanas englobam o sistema de abastecimento de água e esgotos sanitários, a drenagem urbana e as inundações ribeirinhas, a gestão dos sólidos totais, tendo como metas a saúde e conservação ambiental. Nesta seção, inicialmente é apresentada uma visão histórica do desenvolvimento das águas urbanas.

\section{Fases das águas urbanas}

A sociedade agrícola era formada de pequenos grupos ou núcleos que convergiram para as cidades atuais. Até o século XX, o desafio das cidades era evitar a proliferação de doenças, especialmente pelas condições sanitárias dos efluentes da própria população que contaminava suas fontes de abastecimento, criando condições ideais de proliferação de doenças infecciosas.

O abastecimento de água de fontes seguras e a coleta de esgoto, com despejo a jusante ( sem tratamento) do manancial da cidade, tiveram como finalidade evitar doenças e seus efeitos, mas acabaram transferindo os impactos para jusante. Essa fase é chamada de higienista. O crescimento urbano no referido século se acelerou depois da Segunda Guerra Mundial, ocorreu um boom de crescimento populacional, chamado de baby boomer. Esse processo foi seguido da urbanização acelerada, levando uma alta parcela da população para as cidades nesses países, resultando novamente em colapso do ambiente urbano em razão dos efluentes sem tratamento e da poluição aérea.

Para controle desse impacto, no início da década de 1970 houve um marco importante com a aprovação do "Clean Water Act” (Lei de água limpa) nos Estados Unidos. Essa legislação definiu que todos os efluentes deveriam ser tratados com a melhor tecnologia disponível para recuperação e conservação dos rios. Foram realizados investimentos maciços em tratamento de esgoto doméstico e industrial, recuperando em parte a qualidade da água dos sistemas hídricos (rios, lagos, reservatórios e costeiro). Isso permitiu melhorar as condições ambientais, evitar a proliferação de doenças e a deterioração de fontes de abastecimento. Nessa mesma época, verificou-se que era insustentável continuar a construção de obras de drenagem que aumentassem o escoamento em razão 
da urbanização, como a canalização de rios naturais. Procurou-se revisar os procedimentos e utilizar sistemas de amortecimento em detrimento de canalização. Essa tem sido denominada fase corretiva das águas urbanas.

Apesar dessas ações, verificou-se que persistia uma parte da poluição em razão das inundações urbanas e rurais, chamadas de poluição de fontes difusas. Desde os anos 1990, esses países têm investido no desenvolvimento de uma política de desenvolvimento sustentável urbano baseado no tratamento das águas pluviais urbanas e rurais, conservação do escoamento pluvial e tratamento dos efluentes em nível terciário para retirada de nitrogênio e fósforo que eutrofizam os lagos. A base desse desenvolvimento no uso do solo é a implementação da urbanização, preservando os caminhos naturais do escoamento e priorizando a infiltração. Essa fase tem sido denominada desenvolvimento sustentável (Tabela 1).

Tabela 1 - Fases do desenvolvimento das águas urbanas

\begin{tabular}{l|l|l}
\hline Fase & Características & Conseqüências \\
\hline $\begin{array}{l}\text { Pré-higienista: } \\
\text { até início do século XX }\end{array}$ & $\begin{array}{l}\text { Esgoto em fossas ou na } \\
\text { drenagem, sem coleta ou } \\
\text { tratamento e água da fonte } \\
\text { mais próxima, poço ou rio. }\end{array}$ & $\begin{array}{l}\text { Doenças e epidemias, } \\
\text { grande mortalidade e } \\
\text { inundações. }\end{array}$ \\
\hline $\begin{array}{l}\text { Higienista: } \\
\text { antes de 1970 }\end{array}$ & $\begin{array}{l}\text { Transporte de esgoto } \\
\text { distante das pessoas } \\
\text { e canalização do } \\
\text { escoamento. }\end{array}$ & $\begin{array}{l}\text { Redução das doenças, } \\
\text { mas rios contaminados, } \\
\text { impactos nas fontes de } \\
\text { água e inundações. }\end{array}$ \\
\hline $\begin{array}{l}\text { Corretiva: } \\
\text { entre 1970 e 1990 }\end{array}$ & $\begin{array}{l}\text { Tratamento de esgoto } \\
\text { doméstico e industrial, } \\
\text { amortecimento do } \\
\text { escoamento. }\end{array}$ & $\begin{array}{l}\text { Recuperação dos rios, } \\
\text { restando poluição difusa, } \\
\text { obras hidráulicas e impacto } \\
\text { ambiental. }\end{array}$ \\
\hline $\begin{array}{l}\text { Desenvolvimento } \\
\text { sustentável: } \\
\text { depois de 1990 }\end{array}$ & $\begin{array}{l}\text { Tratamento terciário e } \\
\text { do escoamento pluvial, } \\
\text { novos desenvolvimentos } \\
\text { que preservam o sistema } \\
\text { natural. }\end{array}$ & $\begin{array}{l}\text { Conservação ambiental, } \\
\text { redução das inundações e } \\
\text { melhoria da qualidade de } \\
\text { vida. }\end{array}$ \\
\hline
\end{tabular}

Nos países em desenvolvimento, as cidades variam de estágio. Inicialmente, quando a população é pequena, o abastecimento é realizado a partir de poços ou de um corpo d'água próximo, e o esgoto é despejado na drenagem (quando existe) ou evolui para poços negros ou fossas sépticas. Existe o risco de a água de abastecimento ser contaminada pelo próprio esgoto. Esse cenário é dramático quando o solo tem baixa capacidade de infiltração, as fossas não funcionam e o esgoto escoa pelas ruas ou por drenagem. Esse estágio é anterior ao higienismo, o que provoca a proliferação de doenças transmitidas pela água. Nesse estágio préhigienista, doenças como diarréia são a principal causa de mortalidade infantil.

O Brasil infelizmente está ainda na fase higienista em razão de falta de tratamento de esgoto, transferência de inundação na drenagem e falta de controle dos resíduos sólidos. 


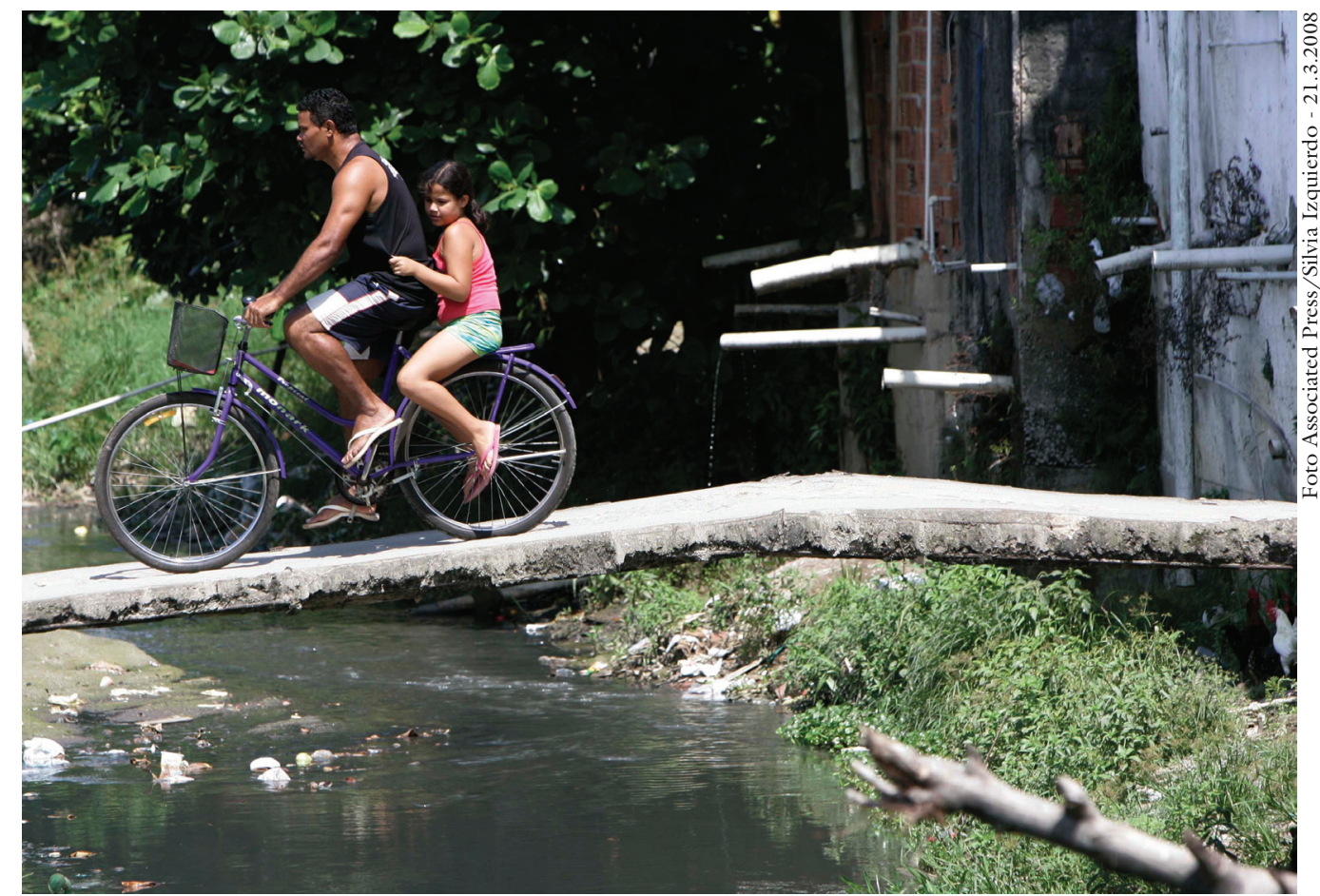

Moradores da favela Curicica, em Jacarepaguá (RJ), jogam esgoto direto no leito do córrego.

\section{Água e esgoto}

Os serviços de água e esgoto no Brasil são resumidos na Tabela 2. Pode-se observar que a cobertura de água é alta no Brasil, mas é baixa a cobertura de coleta e tratamento de esgoto.

Tabela 2 - Cobertura de atendimento de água e esgoto em \%

\begin{tabular}{l|c|c|c|c|c|c}
\hline \multicolumn{1}{c|}{ Tipo } & Urbano & & Rural & & Total & \\
\cline { 2 - 7 } & Cobertura & $\mathrm{D}^{5}$ & Cobertura & $\mathrm{D}^{5}$ & Cobertura & $\mathrm{D}^{5}$ \\
\hline População (milhões) & $\begin{array}{c}152 \\
(83 \%)\end{array}$ & $\%$ & $31,6(17 \%)$ & $\%$ & 183,60 & $\%$ \\
\hline $\begin{array}{l}\text { Abastecimento de } \\
\text { água1 (\%) }\end{array}$ & 91,95 & 8,15 & 88,443 & 11,56 & 91,35 & 8,65 \\
\hline Coleta de esgoto1 (\%) & 77,22 & 22,78 & 18,43 & 81,57 & 67,10 & 32,9 \\
\hline Rede (\%) & 54,27 & & 4,08 & & 45,63 & \\
\hline Fossas (\%) & 22,95 & & 14,35 & & 21,47 & \\
\hline Tratamento de esgoto ${ }^{2(\%)}$ & & & & & $28,2^{4}$ & 81,8 \\
\hline
\end{tabular}

Fonte: Adaptada de Esbe (2006) e SNIS (2004).

1. Proporção obtida segundo os domicílios de levantamento IBGE para 2005; 2. obtido como proporção de entidades amostradas pelo SNIS; 3. cobertura de água + água de fonte segura; 4. esse porcentual se refere ao total coletado e não ao total de esgoto; 5 . déficit de atendimento. 
Os serviços de água possuem problemas crônicos: preservação dos mananciais urbanos, perda de água na distribuição e falta de racionalização de uso da água em nível doméstico e industrial.

O desenvolvimento urbano tem produzido um ciclo de contaminação, gerado pelos efluentes da população urbana, que são o esgoto doméstico/industrial e o esgoto pluvial. Esse processo ocorre em razão de:

- Despejo sem tratamento dos esgotos sanitários nos rios, contaminando este sistema hídrico.

- O esgoto pluvial transporta grande quantidade de poluição orgânica e de metais que atingem os rios nos períodos chuvosos.

- Contaminação das águas subterrâneas por despejos industriais e domésticos, por meio das fossas sépticas, vazamento dos sistemas de esgoto sanitário e pluvial, entre outros.

- Depósitos de resíduos sólidos urbanos, que contaminam as águas superficiais e subterrâneas, funcionando como fonte permanente de contaminação.

- Ocupação do solo urbano sem controle do seu impacto sobre o sistema hídrico.

Com o tempo, locais que possuem abastecimento tendem a reduzir a qualidade da sua água ou exigir maior tratamento químico da água fornecida à população. Portanto, mesmo existindo hoje uma boa cobertura do abastecimento de água no Brasil, essa pode ficar comprometida se medidas de controle do ciclo de contaminação não ocorrerem.

A legislação de proteção de mananciais aprovada na maioria dos Estados brasileiros protege a bacia hidrográfica utilizada para abastecimento das cidades. Nessas áreas, é proibido o uso do solo urbano que possa comprometer a qualidade da água de abastecimento.

Por causa do crescimento das cidades, essas áreas foram pressionadas à ocupação pelo valor imobiliário da vizinhança e pela falta de interesse do proprietário em proteger a área, já que essa perdeu o valor em razão da legislação e ainda necessita pagar impostos que recaem sobre ela. Essas áreas são invadidas pela população de baixa renda, e a conseqüência imediata é o aumento da poluição. Muitos proprietários incentivaram a invasão até para poder vender a propriedade para o poder público.

A principal lição que se pode tirar desse cenário é que, ao se declarar de utilidade pública a bacia hidrográfica do manancial, essa deveria ser adquirida pelo poder público ou criar valor econômico para propriedade, mediante a geração de mercado indireto para a área (mercado de compensação ambiental, solo criado etc.), ou ainda outros beneficios para os proprietários, para compensar a proibição pelo seu uso e incentivá-lo a preservá-la. Por exemplo, no Sul ou Sudeste a disponibilidade hídrica média é de $201 . \mathrm{s}^{-1} \cdot \mathrm{km}^{-2}$. Considerando $60 \%$ desse valor como a vazão regularizada, 1 ha permite abastecer sessenta pessoas ou quinze 
famílias. A área poderia ser alugada por $0,5 \%$ do valor da propriedade por mês com o compromisso do proprietário de preservar a área em condições naturais. O valor do aluguel representaria um aumento do valor do preço da conta de água de $5 \%$ a $15 \%$. Esse aumento seria o preço a ser pago para garantir a qualidade da água ao longo do tempo.

A cobertura de coleta de esgoto é de $77 \%$ se forem consideradas as fossas (Tabela 2), mas a cobertura de tratamento de esgoto é baixa, comprometendo a qualidade da água, já que contamina os mananciais. Considerando o total da demanda da população de água, a sua carga resultante tratada antes de despejada nos rios é seguramente inferior a $15 \%{ }^{2}$ Isso resulta em sete a onze mil toneladas ${ }^{3}$ de $\mathrm{DBO}$ despejados por dia nos sistemas hídricos brasileiros. Essa poluição provoca doenças de veiculação hídrica e deterioração do ambiental natural. Cada habitante está recebendo um subsídio ambiental por não pagar pelos seus impactos.

No Brasil, as empresas de saneamento nos últimos anos têm investido em redes de coleta de esgoto e estações de tratamento, mas a parcela do volume gerado pelas cidades que efetivamente é tratado antes de chegar ao rio é ainda muito pequena. Algumas das questões são as seguintes:

- Quando as redes de esgoto são implementadas ou projetadas, muitas vezes não foi prevista a ligação da saída das habitações ou dos condomínios a elas. Dessa forma, as redes não coletam o esgoto projetado e as estações não recebem o esgoto para o qual têm a capacidade. O projeto foi elaborado de forma inadequada ou não foi executado como deveria, pois o esgoto continua escoando pelo pluvial para o sistema fluvial.

- Como uma parte importante das empresas cobra pelo serviço de coleta e tratamento, mesmo sem que o tratamento seja realizado, qual será o interesse das empresas em completar a cobertura de coleta e tratamento do esgoto? Outro cenário freqüente é o de aumentar a coleta sem tratamento, agravando o problema à medida que concentra a poluição nos rios. Do mesmo modo, qual é o interesse da empresa na eficiência na redução das perdas se pode transferir os custos para o preço final? Como a empresa terá interesse em reduzir a demanda por racionalização, se isso representará menor receita? Observa-se a falta de indicadores de eficiência para os serviços e de compensações para essa eficiência à medida que a água é racionalizada.

- Quando for implementado o sistema de cobrança pela poluição, quem irá pagar as penas previstas para a poluição gerada?

Essas questões geralmente estão relacionadas com a gestão dos serviços e o desenvolvimento socioeconômico.

\section{Drenagem urbana e inundações urbanas}

O escoamento pluvial pode produzir inundações e impactos nas áreas urbanas em razão de dois processos, que ocorrem isoladamente ou combinados: 
- Inundações de áreas ribeirinhas: são inundações naturais que ocorrem no leito maior dos rios por causa da variabilidade temporal e espacial da precipitação e do escoamento na bacia hidrográfica;

- Inundações em razão da urbanização: são as inundações que ocorrem na drenagem urbana por causa do efeito da impermeabilização do solo, canalização do escoamento ou obstruções ao escoamento.

Inundações de áreas ribeirinhas - Os rios geralmente possuem dois leitos: o leito menor, onde a água escoa na maior parte do tempo, é limitado pelo risco de 1,5 a dois anos. As inundações ocorrem quando o escoamento atinge níveis superiores ao leito menor, atingindo o leito maior. As cotas do leito maior identificam a magnitude da inundação e seu risco. Os impactos pela inundação ocorrem quando essa área de risco é ocupada pela população (Figura 1). Esse tipo de inundação geralmente ocorre em bacias médias e grandes $\left(>100 \mathrm{~km}^{2}\right)$.

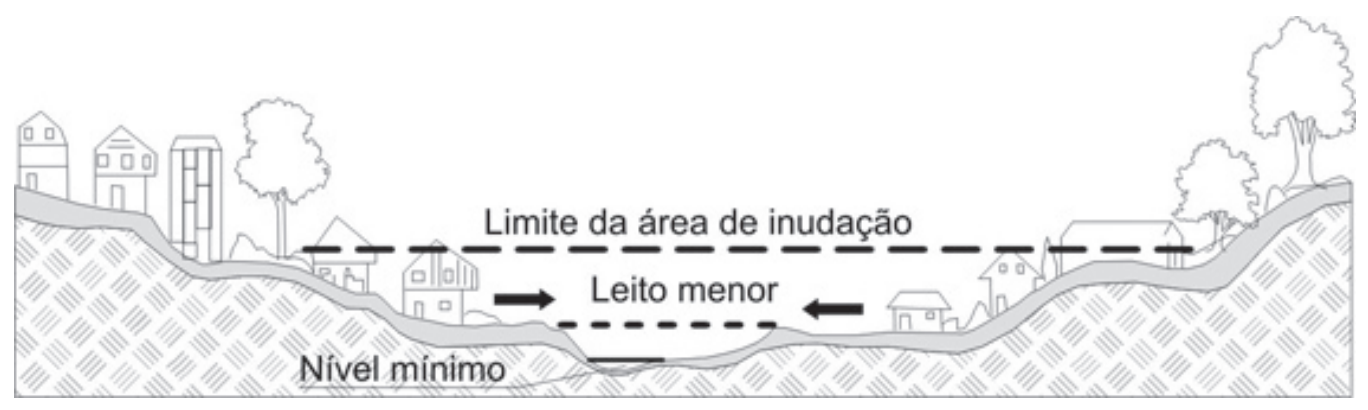

Figura l - Características dos leitos do rio.

Essas condições ocorrem em razão das seguintes ações:

- No Plano Diretor de Desenvolvimento Urbano das cidades, geralmente não existe nenhuma restrição quanto à ocupação das áreas de risco de inundação, a seqüência de anos sem enchentes é razão suficiente para que empresários desmembrem essas áreas para ocupação urbana.

- Invasão de áreas ribeirinhas, que pertencem ao poder público, pela população de baixa renda.

- Ocupação de áreas de médio risco, de freqüência menor, mas quando ocorre inundação sofrem prejuízos significativos.

O gerenciamento atual não incentiva a prevenção desses problemas, já que, à medida que ocorre a inundação, o município declara calamidade pública e recebe recurso a fundo perdido. Para gastar os recursos, não é preciso realizar concorrência pública. Como a maioria das soluções sustentáveis passa por medidas não-estruturais, que envolvem restrições à população, dificilmente um prefeito buscará esse tipo de solução, porque geralmente a população espera por uma obra. Ao passo que, para implementar as medidas não-estruturais, ele teria que interferir em interesses de proprietários de áreas de risco, que politicamente é complexo em nível local. 
Para buscar modificar esse cenário, é necessário um programa em nível estadual ou federal para apoiar tecnicamente as soluções dos municípios, e a educação da população, além de atuação junto aos bancos que financiam obras em áreas de risco.

Inundações por causa de urbanização - As enchentes aumentam a sua freqüência e magnitude em razão da impermeabilização do solo e da construção da rede de condutos pluviais. O desenvolvimento urbano pode também produzir obstruções ao escoamento, como aterros, pontes, drenagens inadequadas, obstruções ao escoamento junto a condutos e assoreamento. Geralmente essas inundações são vistas como locais porque envolvem bacias pequenas $\left(<100 \mathrm{~km}^{2}\right.$, mas freqüentemente bacias $<10 \mathrm{~km}^{2}$ ).

À medida que a cidade se urbaniza, em geral, ocorrem os seguintes impactos:

- Aumento das vazões máximas (Figura 2) em várias vezes e da sua freqüência em virtude do aumento da capacidade de escoamento através de condutos e canais e impermeabilização das superfícies.

- Aumento da produção de sedimentos pela falta de proteção das superfícies e pela produção de resíduos sólidos (lixo).

- A deterioração da qualidade da água superficial e subterrânea, em razão de lavagem das ruas, transporte de material sólido e de ligações clandestinas de esgoto cloacal e pluvial.

- Por causa da forma desorganizada como a infra-estrutura urbana é implantada, tais como: (a) pontes e taludes de estradas que obstruem o escoamento; (b) redução de seção do escoamento por aterros de pontes e para construções em geral; (c) deposição e obstrução de rios, canais e condutos por lixos e sedimentos; (d) projetos e obras de drenagem inadequadas, com diâmetros que diminuem a jusante, drenagem sem esgotamento, entre outros.

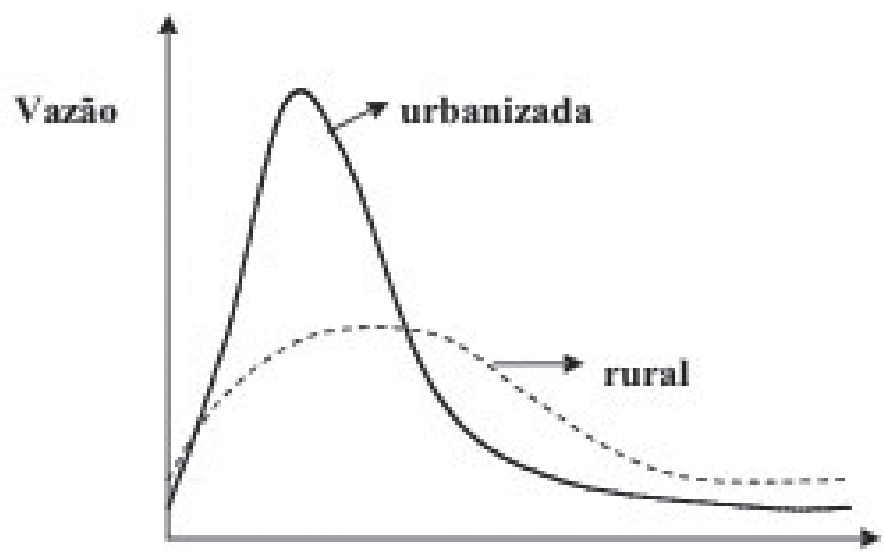

Tempo

Figura 2 - Hidrograma de bacia rural e depois de urbanizada. 


\section{Os sólidos totais}

Os dois tipos principais de sólidos são os sedimentos gerados pela erosão do solo, em razão do efeito da precipitação e do sistema de escoamento, e os resíduos sólidos produzidos pela população. A soma desses dois componentes é chamada de sólidos totais.

No desenvolvimento urbano, são observados alguns estágios distintos da produção de material sólido na drenagem urbana, como seguem:

a) estágio de pré-desenvolvimento: a bacia hidrográfica naturalmente produz uma quantidade de sedimentos transportada pelos rios em razão das funções naturais do ciclo hidrológico;

b) estágio inicial de desenvolvimento urbano: quando ocorre modificação da cobertura da bacia, pela retirada da sua proteção natural, o solo fica desprotegido e a erosão aumenta no período chuvoso, aumentando também a produção de sedimentos. Exemplos dessa situação são: enquanto um loteamento é implementado, o solo fica desprotegido; ruas sem pavimento; erosão pelo aumento da velocidade do escoamento a montante por áreas urbanizadas; na construção civil por falta de manejo dos canteiros de obras onde ocorre grande movimentação de terra. Esse volume é transportado pelo escoamento superficial até os rios. Nessa fase, existe predominância dos sedimentos e pequena produção de lixo;

c) estágio intermediário: parte da população está estabelecida, ainda existe importante movimentação de terra por causa de novas construções. Em virtude da população estabelecida, existe também uma parcela de resíduos sólidos que se soma aos sedimentos;

d) estágio de área desenvolvida: nessa fase praticamente todas as superfícies urbanas estão consolidadas, resultando numa produção residual de sedimentos em razão das áreas não-impermeabilizadas, mas a produção de lixo urbano chega ao seu máximo com a densificação urbana.

\section{Qualidade da água do pluvial}

A quantidade da água na drenagem pluvial possui uma carga poluente alta por causa das vazões envolvidas. O volume dessas vazões é mais significativo no início das enchentes. Os primeiros $25 \mathrm{~mm}$ de escoamento superficial geralmente transportam grande parte da carga poluente ${ }^{4}$ de origem pluvial (Schueller, 1987).

Uma das formas de avaliar a qualidade da água urbana é pelos parâmetros que caracterizam a poluição orgânica e a quantidade de metais. Schueller (1987) cita que a concentração média dos eventos não se altera em razão do volume do evento, sendo característico de cada área drenada.

A rede de esgoto pode ser combinada (sanitário e pluvial num mesmo conduto) ou separada (rede pluvial e sanitária separada). A legislação estabelece o sistema separador, mas na prática isso não ocorre em razão das ligações clan- 
destinas e da falta de rede de esgoto sanitário. Por causa da falta de capacidade financeira para implantação da rede de esgoto, algumas prefeituras têm permitido o uso da rede pluvial para transporte do esgoto sanitário, o que pode ser uma solução inadequada à medida que esse esgoto não é tratado. Quando o sistema sanitário é implementado, a grande dificuldade envolve a retirada das ligações existentes da rede pluvial, o que na prática resulta em dois sistemas misturados com diferentes níveis de carga.

A qualidade da água da rede pluvial depende de vários fatores: da limpeza urbana e sua freqüência; da intensidade da precipitação e sua distribuição temporal e espacial; da época do ano e do tipo de uso da área urbana.

\section{Gestão das águas urbanas}

A gestão das ações dentro do ambiente urbano pode ser definida de acordo com a relação de dependência da água através da bacia hidrográfica ou da jurisdição administrativa do município, do Estado ou da nação. A tendência da gestão dos recursos hídricos tem sido realizada através da bacia hidrográfica, no entanto a gestão do uso do solo é realizada pelo município ou grupo de municípios numa Região Metropolitana. A gestão pode ser realizada de acordo com a definição do espaço geográfico externo e interno à cidade.

Os planos das bacias hidrográficas têm sido desenvolvidos para bacias grandes $\left(>1.000 \mathrm{~km}^{2}\right)$. Nesse cenário, existem várias cidades que interferem umas nas outras, transferindo impactos. O plano da bacia dificilmente poderá envolver todas as medidas em cada cidade, mas deve estabelecer os condicionantes externos às cidades, como a qualidade de seus efluentes, as alterações de sua quantidade, que visem à transferência de impactos. $\mathrm{O}$ mecanismo, já previsto na legislação, para gestão dos impactos da qualidade da água externa às cidades é o enquadramento do rio dentro dos padrões do Conama. No entanto, esses padrões não estabelecem padrões para controle do aumento da vazão por causa da urbanização.

A gestão do ambiente interno da cidade trata de ações dentro do município para atender aos condicionantes externos previstos no Plano de Bacia para evitar os impactos. Esses condicionantes geralmente buscam minimizar os impactos da quantidade e melhorar a qualidade da água no conjunto da bacia, além dos condicionantes internos que tratam de evitar os impactos à população da própria cidade. Para esses dois espaços existem gestores, os instrumentos utilizados e as metas da gestão, como descrito na Tabela 3. A construção global dessa estrutura de gestão esbarra em algumas dificuldades:

- Limitada capacidade dos municípios para desenvolverem a gestão, considerando a maioria desses.

- O sistema de gestão das bacias ainda não é uma realidade consolidada na maioria dos países da América do Sul.

- Reduzida capacidade de financiamento das ações pelos municípios e o alto nível de endividamento. 
Tabela 3 - Espaço de gestão das águas urbanas

\begin{tabular}{l|l|l|l|l}
\hline Espaço & Domínio & Gestores & Instrumento & Característica \\
\hline $\begin{array}{l}\text { Bacia } \\
\text { hidrográfica1 }\end{array}$ & $\begin{array}{l}\text { Estado ou } \\
\text { governo } \\
\text { federal }\end{array}$ & $\begin{array}{l}\text { Comitê e } \\
\text { agências }\end{array}$ & $\begin{array}{l}\text { Plano de } \\
\text { bacia }\end{array}$ & $\begin{array}{l}\text { Gestão da quantidade } \\
\text { e qualidade da água } \\
\text { nos rios da bacia } \\
\text { hidrográfica, sem } \\
\text { transferir impactos. }\end{array}$ \\
\hline Município $^{2}$ & $\begin{array}{l}\text { Município } \\
\text { ou Região } \\
\text { Metropolitana }\end{array}$ & Município & $\begin{array}{l}\text { Plano Diretor } \\
\text { Urbano } \\
\text { e Plano } \\
\text { Integrado de } \\
\text { Esgotamento, } \\
\text { Drenagem } \\
\text { Urbana } \\
\text { e Resíduo } \\
\text { Sólido }\end{array}$ & $\begin{array}{l}\text { Minimizar os impactos } \\
\text { dentro da cidade, } \\
\text { nas pequenas bacias } \\
\text { urbanas e não transferir } \\
\text { para o sistema de rios. }\end{array}$ \\
\hline
\end{tabular}

1. Bacias de grande porte $\left(>1.000 \mathrm{~km}^{2}\right) ; 2$. área de abrangência do município e suas pequenas sub-bacias de macrodrenagem $\left(<50 \mathrm{~km}^{2}\right)$. Os valores de áreas são indicativos e podem se alterar para cidades de grande porte.

No primeiro caso, a solução passa pelo apoio estadual e federal mediante escritórios técnicos que apóiem as cidades de menor porte no desenvolvimento de suas ações de planejamento e implementação. O segundo dependerá da transição e evolução do desenvolvimento da gestão no país. O terceiro dependerá fundamentalmente do desenvolvimento de um programa em nível federal e mesmo estadual, com um fundo de financiamento para viabilizar as ações.

\section{Tendências}

As metas do milênio propostas pelas Nações Unidas envolvem vários aspectos nos quais a gestão das águas urbanas faz parte. Os principais são: (a) redução da falta de água potável e coleta e tratamento de esgoto em $50 \%$ até 2015; (b) redução da pobreza, em que a vulnerabilidade a eventos naturais e antrópicos tem peso muito grande, já que a vulnerabilidade a secas e inundações é um dos principais fatores de pobreza. Para atingir as Metas do Milênio em 2002 em Johanesburgo foi estabelecido que os países deveriam buscar desenvolver Planos de Recursos Hídricos para atingir as várias metas. Esses planos na realidade envolviam desenvolver a gestão dos recursos hídricos nos países.

O Brasil evoluiu no processo quanto à Gestão de Recursos Hídricos, pois ao implantar a Lei de Recursos Hídricos deu o primeiro passo instituindo o mecanismo amplo de gestão das águas, criou os instrumentos como outorga, cobrança e enquadramento dos rios (metas de qualidade da água), estabelecendo as condições de contorno para as cidades quanto à contaminação dos rios. Recentemente concluiu o Plano Nacional de Recursos Hídricos (MMA, 2006) e foi aprovada (janeiro de 2007) uma nova Legislação de Saneamento Ambiental que 
integra os mecanismos econômicos. Implementou as instituições como a Agência Nacional de Águas e estão em andamento as agências estaduais e os Conselhos e Comitês de bacia. Portanto, o processo está se encaminhando de forma adequada. No entanto, no âmbito das ações no saneamento observa-se o seguinte:

a) Atualmente no país existe um universo de várias cidades com serviços privatizados (empresas de direito privado é da ordem de 10\%), com serviços públicos municipais e a grande maioria com serviços de empresas públicas estaduais. As empresas estaduais representam aproximadamente $82 \%$ da população atendida para abastecimento e $77 \%$ da população no esgoto (Ipea, 2002).

b) A cobertura de coleta de esgoto é média se forem consideradas as fossas, mas baixa cobertura de tratamento de esgoto que compromete o todo, já que contamina os mananciais.

c) A vulnerabilidade a eventos pluviais das cidades é alta, o que agrava a situação de pobreza na periferia das cidades. Os maiores prejuízos não são necessariamente materiais, mas sociais.

Para que o país possa atingir as metas do milênio e aumentar o abastecimento e o atendimento de coleta e tratamento de esgoto reduzindo esse déficit em 50\% até 2005, seria necessário atuar especialmente sobre o seguinte:

- Aumentar o abastecimento de água na área rural e da população de baixa renda, buscando atingir os níveis de cobertura total de água segura.

- O déficit em coleta de esgoto é ainda de 32,9\%; portanto, para buscar as metas, representaria reduzir esse déficit para 16,4\%.

- O maior problema, no entanto, se encontra na redução no tratamento de esgoto, cujo déficit se encontra em $81,8 \%$. Dentro da metas do milênio representaria reduzir para $40,9 \%$.

Estudo realizado pelo PMSS em 2003-2004 (apud Esbe, 2006) menciona a necessidade de um investimento de R\$ 178 bilhões em vinte anos para atingir a universalização, representando $0,6 \%$ do PIB. Tucci (2005a) apresentou a necessidade de investimento para um Programa Nacional de Águas Pluviais que controlasse os impactos na drenagem e inundação das cidades, e identificou um total de R\$ 21,5 bilhões em 24 anos para solução desses impactos, representando até $0,2 \%$ do PIB num ano. Com base nessas estimativas, é possível antever a necessidade de investimentos da ordem de $0,8 \%$ do PIB para o saneamento ambiental (sem incluir resíduos sólidos). Essa quantia representaria a ordem de R\$ 16 bilhões por ano em água, esgoto e drenagem para, no horizonte de aproximadamente vinte anos, existir um processo sustentável de desenvolvimento urbano. Caso esse investimento fosse realizado como previsto em Tucci (2005a), iniciando com as cidades maiores para as menores em termos prioritários, as maiores cargas seriam contidas nos próximos anos.

A evolução da cobertura dos serviços nos últimos cinco anos ( 1\% ), no entanto, é inferior ao crescimento habitacional brasileiro (2001-2005), o que tem 
levado a um aumento do déficit e não necessariamente a uma redução (Esbe, 2006). As principais dificuldades existentes são relacionadas com:

a) Aspectos institucionais relacionados com a gestão das companhias, mudança de legislação e falta de eficiência dos serviços na medida em que não existem parâmetros, metas bem definidas de atendimento e eficiência dos serviços. A ineficiência é transferida aos usuários, já que os serviços não possuem competitividade.

b) Econômico-financeiro, como o contingenciamento dos recursos e a capacidade de endividamento dos municípios e financiamento permanente.

Atualmente falta integrar efetivamente as metas da Gestão dos Recursos Hídricos às do Saneamento Ambiental. Apesar de essa integração estar implicitamente prevista na legislação, na prática não ocorre. O Plano da Bacia Hidrográfica prevê o enquadramento dos rios, e as cidades deveriam atuar no controle dos efluentes urbanos para atingir a meta do enquadramento dos rios internos e externos à bacia. No entanto, é necessário que existam planos e que estes enquadrem os rios nos quais as cidades influenciam, seguidos de um plano de ações para atingir as metas.

\section{Notas}

l Os sistemas urbanos são áreas delimitadas, caracterizadas por alta densidade populacional sustentadas por processos biofísicos com origem e abrangência maior que a área urbana (Rees, 2003).

2 Para um total de coletado de $50,6 \%$ e tratado de $28,2 \%$ do coletado (SNIS, 2004) e eficiência de $75 \%$ quanto à redução da carga, há $10,7 \%$ de carga efetivamente tratada.

3 Considerando a carga de 183,6 milhões de pessoas, concentração de $250 \mathrm{mg} / \mathrm{l}$ de DBO, consumo de $250 \mathrm{l} /$ dia e retorno de $80 \%$, há um resultado de 8,197 mil toneladas por dia, é parte é despejada em fossas 25\%.

4 Carga é o produto da vazão pela concentração da substância poluente.

\section{Referências bibliográficas}

ESBE. PNAD 2005 aumenta o déficit de dos serviços de saneamento básico. Projeções indicam universalização em 50 anos. ESBE Associação das Empresas de Saneamento Estaduais, 2006.

IBGE. Anuário estatístico do Brasil - 1997. Rio de Janeiro: Instituto Brasileiro de Geografia e Estatística, 1998. (CD-ROM).

IPEA. Diagnóstico dos Serviços de Água e Esgotos 2001. Sistema Nacional de Informações sobre Saneamento. Programa de Modernização do Setor de Saneamento, 2002.

MMA. Cidades sustentáveis: subsídios à elaboração da Agenda 21 Brasileira. Brasília: Ministério de Meio Ambiente. 2000. 155p.

MMA. Plano Nacional de Recursos Hídricos. Brasília: Secretaria de Recursos Hídricos. Ministério do Meio Ambiente, 2006. 
REES, W. E. Understanding urban ecosystems: an ecologic economics perspective. In: BERKOWITZ, A. R.; NILON, C. H.; KOLLWEG, K. S. (Ed.) Understanding Urban Ecosystems: a new frontier for sciences and education. New York: Spriger-Verlang, 2003. p.115-36.

SCHUELER, T. Controlling urban runoff: a practical manual for planning and designing urban BMP. Washington, DC: Metropolitan Washington Council of Governments, 1987.

SNIS. Diagnóstico dos serviços de água e esgoto - 2003. Brasília: PMSS Programa de Modernização do Setor de Saneamento. Ministério das Cidades, 2004.

TIETENBERG, T. Environmental and natural resource economics. Boston: Addison Wesley, 2003. 646p.

TUCCI, C. E. M. Programa de drenagem sustentável: apoio ao desenvolvimento do manejo das águas pluviais urbanas - Versão 2.0. Brasília: Ministério das Cidades, 2005a.

Desenvolvimento dos recursos hídricos no Brasil. REGA, v.2, n.2, dez. 2005b.

RESUMO - As águas urbanas geralmente incluem abastecimento de água e saneamento. Nessa perspectiva, saneamento envolve a coleta de tratamento de efluentes domésticos e industriais, não inclui drenagem urbana, gestão dos resíduos sólidos, porque ainda perdura uma visão desatualizada da gestão das águas urbanas da cidade. Águas urbanas envolvem componentes que permitem o desenvolvimento ambiental sustentável e utilizam os conceitos da gestão integrada dos recursos hídricos (GIRH), necessários para planejamento, implementação e manutenção da infra-estrutura da cidade. Nesse contexto, ficam denominados Gestão Integrada das Águas Urbanas. Neste artigo, analisam-se o desenvolvimento urbano e suas relações com as águas urbanas no Brasil. A gestão dos recursos hídricos no Brasil é realizada por bacias hidrográficas, e o domínio é federal ou estadual. Examinam-se as possibilidades de gestão da água na cidade e na bacia hidrográfica no contexto institucional brasileiro.

PALAVRAS-CHAVE: Gestão, Urbanização, Água, Saneamento.

ABSTRACT - Urban Waters systems generally include both water supply \& sanitation facilities (WSS). Sanitation refers to domestic and industrial sewage collecting and treatment; it does not include urban stormwater or solid waste management systems. Urban water form components of a sustainable urban environment and the use of the integrated water resource management (IWRM) concepts are needed for planning, implementation and maintenance of urban infrastructure. In urban environment, IWRM is referred to specifically as Integrated Urban Water Management (IUWM). In this paper urban development and its relations with urban waters in Brazil are assessed. Management of Water Resources in Brazil is developed by basins and the administration is Federal or from the state. This article assess the alternatives of water management in the city and the basin in the Brazilian institutional environment.

KErWORDS: Management, Urbanization, Water suppy, Sannitary.

Carlos E. M. Tucci é professor do Instituto de Pesquisas Hidráulicas, da Universidade Federal do Rio Grande do Sul (UFRGS). @ - tucci@iph.ufrgs.br

Recebido em 16.6.2008 e aceito em 23.6.2008. 